\title{
Physical Fitness and Physical Activity in Swedish Women before and one Year after Roux-en-Y Gastric Bypass Surgery
}

\author{
Malin Wiklund ${ }^{\mathrm{a}, *}$, Monika F. Olsén ${ }^{\mathrm{a}}$, Torsten Olbers ${ }^{\mathrm{b}}$ and Åsa Cider $^{\mathrm{a}}$ \\ ${ }^{a}$ Department of Physiotherapy and Occupational Therapy, Sahlgrenska University Hospital, and Institute of \\ Neuroscience and Physiology/Physiotherapy, Sahlgrenska Academy, University of Gothenburg, Gothenburg, Sweden \\ ${ }^{b}$ Department of Surgery, Sahlgrenska University Hospital, Gothenburg, Sweden
}

\begin{abstract}
Introduction: Obesity is associated with a sedentary life style, which has a negative impact on physical fitness.
Aim: To investigate physical fitness, physical activity level and time spent sitting in Swedish women before and one year after laparoscopic Roux-en-Y Gastric Bypass surgery (LRYGB).

Method: Thirty-seven women (age: $41.2 \pm 9.6$ years and Body Mass Index (BMI): $42 \pm 6.5 \mathrm{~kg} / \mathrm{m}^{2}$ ) were tested before and one year after LRYGB. (BMI: $30.5 \pm 5.8 \mathrm{~kg} / \mathrm{m}^{2}$ ). Physical fitness was assessed using the six minute walk test (6MWT), and three muscular endurance and one handgrip test. Physical activity level and sitting time were assessed using the short form of the International Physical Activity Questionnaire (IPAQ).

Results: One year after surgery the mean distance walked during 6MWT increased from $532 \mathrm{~m}$ to $599 \mathrm{~m}(\mathrm{p}=<0.001)$ and the muscular endurance was significantly improved ( $\leq 0.016$ ), while no statistical significant difference was found in grip force compared to pre-operatively. After surgery, the women walked significantly more minutes/week $(\mathrm{p}=0.018)$ and increased their level of moderate $(\mathrm{p}=0.039)$ and vigorous $(\mathrm{p}=0.033)$ physical activity, but there were no significant differences in sitting time ( $\mathrm{p}=0.206$ ) compared to preoperatively.

Conclusions: The physical activity level as well as physical fitness increased while grip strength remained same in Swedish women one year after LRYGB, compared to before surgery. The improved physical fitness and the considerable weight loss are important factors in reducing the risk of developing lifestyle associated diseases and risk of premature death in this group of women. But even if both physical activity and physical fitness increased at group level one year after LRYGB, some individuals still needed to be more physically active and to enhance the physical fitness level. These patients might benefit from physiotherapy to be able to be more physically active.
\end{abstract}

Keywords: Gastric bypass surgery, muscular endurance, muscular strength, obesity, physical activity, physical fitness.

\section{INTRODUCTION}

Obesity is often associated with low levels of physical activity and a sedentary life style that has a negative impact on physical fitness. For most individuals, an increased physical activity results in an improved physical fitness, even if the amount of adaptation in physical fitness to a certain exercise program varies widely and is under genetic control [1]. The health-related components of physical fitness are cardiorespiratory endurance, muscular endurance, muscular strength, body composition, and flexibility [2]. In this study, we focus on cardiorespiratory endurance, muscular endurance and muscular strength.

It is still largely unknown whether a bariatric surgeryinduced decrease in BMI affects muscle endurance and muscle strength in women. It has, however, been shown that

*Address correspondence to this author at the Department of Physiotherapy, Sahlgrenska University Hospital, 41345 Gothenburg, Sweden;

Tel: 004631 3421195; Fax: 00463134243 41;

E-mail: malin.wiklund@vgregion.se in men this intervention is associated with a significant decline in muscular strength, particularly in the lower limbs, one year after surgery [3].

Bariatric surgery has been found to improve the distance walked during the six minute walk test (6MWT) [4-6]. One of the purposes of this study was to find out whether this could be shown in a Swedish population of women.

The World Health Organization (WHO) recommends that adults should participate in $\geq 150$ minutes of at least moderate intensity aerobic physical activity throughout the week to reduce the risk of chronic disease [7]. It has previously been shown that one year after LRYGB surgery, $57 \%$ of the American patients were physically active on a moderate or higher intensity level $\geq 150$ minutes/week, while $26 \%$ of the patients reported no physical activity on a moderate or higher intensity level as assessed by the International Physical Activity Questionnaire (IPAQ) [8]. It is not yet evaluated to what extent Swedish women fulfill the WHO recommendation before or one year after laparoscopic Roux-en-Y Gastric Bypass surgery (LRYGB). 
The risk for all cause mortality, independent of sex, age, physical activity level and body mass index (BMI) increases when time spent sitting increases [9]. One study showed that American patients awaiting bariatric surgery spent $81.4 \%$, or 10.9 hours/day, of their objectively monitored time (13.3 hours/dag) sedentary, i.e. sitting [10]: In comparison the average American spent $54.9 \%$, or 7.7 hours/day, of monitored time (13.9 hours/day) in sedentary behaviors [11]. It is not known how many hours/day Swedish women sit before and one year after LRYGB.

This study aimed therefore to investigate physical fitness, physical activity level and time spent sitting in Swedish women before and one year after LRYGB.

\section{METHOD}

This investigation was part of a larger clinical study, assessing excess skin and physical activity level in 200 men and women before as well as after 12 and 18 months post LRYGB performed at Sahlgrenska University Hospital Gothenburg, Sweden during May 2009 to December 2011. The large clinical study had the following inclusion criteria: estimated LRYGB surgery within the next three months and the subjects able to understand spoken and written Swedish. The exclusion criteria were earlier surgery in the abdomen or a skin disease. The results from this study are not yet analyzed and not a focus of this study. During Feb 2010 to December 2011, all 87 women who wanted to participate in the large clinical study were also invited to participate in this study and an extra exclusion criterion was adopted: neurological, rheumatologic or orthopedic injury or illness that would hinder the assessments. The women received both written and verbal information about the studies and inclusion and exclusion criteria from a nurse during a preoperative preparation day at the department of surgery. Of the 87 women invited, 47 women wanted to participate in this study and all fulfilled the inclusion criteria.

The Regional Ethical Review Board of Gothenburg, Sweden, approved the study and before starting the study it was registered in a national register for clinical trials.

Each woman was tested, at the same time of the day, in the physiotherapy department one month before and 12 months after the LRYGB. First, height and weight were measured in light clothing and no shoes, using a wallmounted stadiometer (Seca, Hamburg, Germany) and a calibrated physician's scale (TANITA, Tokyo, Japan). Body mass index (BMI) was then calculated. Circumference measures of the waist and hip were performed according to WHO standards [12] using a measuring tape. The first author performed all measurements.

To avoid carryover effects between the tests and between tested extremities the order of the below given tests was randomized in a random order table, using Microsoft Excel 2010, before the study started.

\section{PHYSICAL FITNESS}

\section{Cardio Respiratory Endurance}

The 6MWT has been found to be highly reproducible in obese subjects [13]. The 6MWT was performed according to the protocol of the American Thoracic Society in using a 30 $\mathrm{m}$ pre-measured course [14]. Two 6MWTs were performed and the longest distance covered (6MWD) was analyzed. The time between the two tests was at least 1 hour, including a minimum of 20 minutes sitting, or until the resting heart rate (HR) had returned to within $5 \%$ of its baseline value. HR was assessed before and directly after the tests by using an HR monitor (Fs2c, Polar, Kempele, Finland). At the end of each test, exertion was rated using Borg's Rate of Perceived Exertion (RPE) scale [15] and dyspnea and pain were measured using Borg's Category Ratio (CR-10) scale [16].

\section{Muscular Strength}

Grip strength was measured with the "Grippit" instrument (Detector AB, Göteborg, Sweden) which is an electronic force transducer [17]. Both hands were assessed and the highest value out of three was registered [18]. The test-retest reliability of "Grippit" has been found to be good both for healthy women, and for women with rheumatoid arthritis $\left(\mathrm{r}_{\mathrm{s}} \geq 0.88\right)$ [17].

\section{Muscle Endurance}

Endurance of calf muscle was tested by unilateral isotonic heel-lift and that of shoulder muscle was tested by unilateral isotonic shoulder flexion and by bilateral isometric shoulder abduction. These muscular endurance tests are described in detail elsewhere [19]. The test- retest reliability of these tests has been found to be good for both healthy individuals $\left(\mathrm{r}_{\mathrm{s}}=0.79-0.98\right)$ as well as for patients with chronic heart failure $\left(r_{s}=0.90-0.99\right)$ [20].

\section{Physical Activity Level and Sitting Time}

The short form of the International Physical Activity Questionnaire (IPAQ) was administered for measuring physical activity and inactivity during the last seven days before each test. Total weekly physical activity was calculated by taking the reported minutes per week in each activity category and multiplying them by a metabolic equivalent $($ MET) $($ Walking = 3.3 METs, Moderate physical activity $=4.0$ METs and Vigorous physical activity $=8.0$ METs) according to Guidelines [21]. In this study, the cutoff point of being physically active on the recommended level [7] was > 600 total MET-minutes/week. If data was missing for days the case was, in accordance with guidelines [21], removed from the analysis. If number of days was completed but hours/minutes spent were missing, or were not known, 10 minutes was expected, as this was the shortest amount of time considered.

\section{STATISTICAL ANALYSES}

Statistical analyses were carried out using SPSS version 17.0 and the statistical significance level was set at $p<0.05$ (two-sided test). All continuous variables were described as mean and one standard deviation (SD), or median and interquartile range. All categorical variables were described in number and/or percentage. Paired sample T-test or Wilcoxon signed rank test was performed to evaluate differences between pre- and postoperative measurements. 
Table 1. Descriptive data of the participating women preoperative and one year postoperative LRYGB (n=37). Mean (SD).

\begin{tabular}{|c|c|c|c|}
\hline & Preoperatively & 1 year Postoperatively & P-Value \\
\hline Age (year) & $41.2(9.6)$ & $42.2(9.6)$ & \\
\hline Height (m) & $1.66(0.06)$ & $1.66(0.06)$ & \\
\hline Weight (kg) & $116.1(21.2)$ & $83.4(17.7)$ & $<0.001$ \\
\hline BMI $\left(\mathrm{kg} / \mathrm{m}^{2}\right)$ & $42.0(6.5)$ & $30.5(5.8)$ & $<0.001$ \\
\hline Waist-circumference (cm) & $119.9(11.7)$ & $96.0(14.2)$ & $<0.001$ \\
\hline Hip-circumference (cm) & $135.3(13.3)$ & $113.0(12.4)$ & $<0.001$ \\
\hline Waist to hip-ratio & $0.88(0.07)$ & $0.85(0.07)$ & $<0.001$ \\
\hline Resting Heart Rate (beats/min), $n=33$ & $80(9)$ & $71(9)$ & $<0.001$ \\
\hline
\end{tabular}

LRYGB; laparoscopic Roux-en-Y gastric bypass, SD; standard deviation, BMI; body mass index.

Only the results from the women who participated in both assessments were calculated. The heart rate values from the women taking beta-blockers were excluded. Differences in proportions within the group were analyzed with a Chi2-test. Wilcoxon signed rank test was also used when comparing the grip strength of the women in this study with sex and age matched reference values [17]. Spearman correlation coefficient $\left(\mathrm{r}_{\mathrm{s}}\right)$ was used to assess the relationship between the differences in BMI and the differences in physical activity level, the 6MWD and the different muscle tests. Correlation was in this study defined as: little, if any $\left(r_{\mathrm{s}}<0.25\right)$, low $\left(\mathrm{r}_{\mathrm{s}}=0.26-0.49\right)$, moderate $\left(\mathrm{r}_{\mathrm{s}}=0.50-0.69\right)$, high $\left(r_{\mathrm{s}}=0.70-0.89\right)$, and very high $\left(\mathrm{r}_{\mathrm{s}}=0.9-1.00\right)$ [22].

\section{RESULTS}

Of the 47 women measured one month before surgery, three women eventually did not go through surgery due to co-morbidity. Another three women were dropped out and four were not available for follow-up, resulting in 37 women measured both pre- and one year postoperatively. The reasons for withdrawing from the study included personal reasons such as lack of time and travelling distance. The demographic data of included women are presented in Table 1. The 10 women who only performed assessments preoperatively did not significantly differ from the women who completed the study in terms of demographic data, muscular strength, muscular endurance, physical activity level or 6MWD.

\section{Physical Fitness}

Table 2 presents the results of the included tests. The women completed all 6MWTs with no complications or early ends. None of the patients was dyspnoetic at rest, either before or one year after surgery. All women improved their 6MWD one year postoperatively, compared to baseline. The average increase in 6MWD was $67 \mathrm{~m}$ and the minimum increase in 6MWD was $6 \mathrm{~m}$ and the maximum $140 \mathrm{~m}$. HR, perceived exertion and dyspnea were significantly lower and the women experienced significantly less muscular and skeletal pain, particularly in the knees and feet, during the 6MWT one year postoperatively in comparison with baseline.
Heel-lift, shoulder flexion and shoulder abduction improved significantly one year postoperatively.

No statistical differences were found between grip force before or after LRYGB. Also when comparing the preoperative values for grip force with reference values for healthy women [17] there were no statistical differences, either for the right $(\mathrm{p}=0.821)$ or left $(\mathrm{p}=0.459)$ hand before surgery. Corresponding figures one year postoperatively were $(p=0.129)$ for the right and $(p=0.716)$ for the left hand.

\section{Physical Activity Level and Sitting Time}

The IPAQ values, shown in Table 2, are based on the women who answered the current IPAQ question both preand postoperatively. The women in this study walked significantly more minutes/week and were significantly more physically active at vigorous and moderate intensity levels one year postoperatively compared to baseline.

Seventy percent $(22 / 31)$ of the women were physically active > 600 MET-minutes/week pre-operatively, and $82 \%$ $(24 / 29)$ one year postoperatively $(\mathrm{p}>0.05)$.

\section{CORRELATIONS}

There was one significant but low correlation between difference in BMI and the difference in peak grip force left hand $\left(r_{s}=0.416, p=0.028\right)$. No other significant correlations were found between the decrease in BMI and difference in physical activity level/fitness before and one year after LRYGB.

\section{DISCUSSION}

An intentional choice was made to include only women in this study, as it is more common for women to go through LRYGB and muscular strength is partly dependent on sex. Body composition also differs between the sexes, which could affect the measurements. Further studies are needed on men to test if the same results are obtained for both sexes.

Our study demonstrated that women one year after LRYGB significantly increased their mean 6MWD, from $532 \mathrm{~m}$ to $599 \mathrm{~m}$, and that perceived exertion, pain and 
Table 2. 6MWD, peak grip force, unilateral isotonic heel-lift, unilateral isotonic shoulder flexion and bilateral isometric shoulder abduction and IPAQ pre- and one year postoperatively LRYGB; Data are presented as Mean (SD) or Median (IQR).

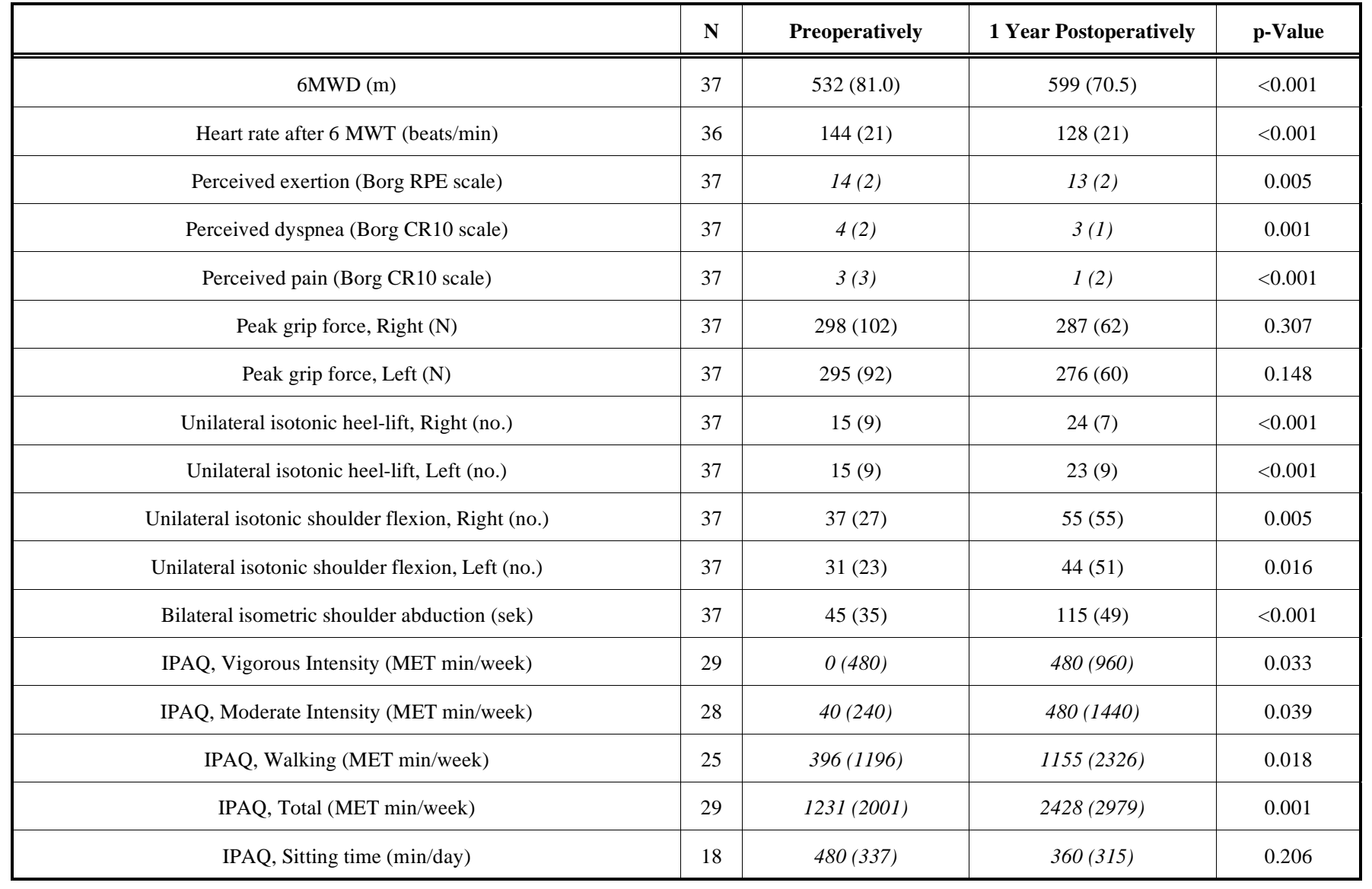

6MWD; 6 Minute Walk Distance, LRYGB; laparoscopic Roux-en-Y gastric bypass, SD; standard deviation, IQR; interquartile range, MET; metabolic equivalent.

dyspnea during the test decreased significantly. The preoperative results from the 6MWD are similar to those measured in Belgian women with severe obesity (BMI 40.7 $\mathrm{kg} / \mathrm{m}^{2}$ ), who had a mean 6MWD of $538.9 \mathrm{~m} \mathrm{[23]} \mathrm{and} \mathrm{a} \mathrm{group}$ of Swedish women (BMI $39.4 \mathrm{~kg} / \mathrm{m}^{2}$ ) whose mean 6MWD was $531 \mathrm{~m} \mathrm{[24].} \mathrm{One} \mathrm{year} \mathrm{postoperatively,} \mathrm{the} \mathrm{women} \mathrm{in} \mathrm{our}$ study had a BMI of $30.9 \mathrm{~kg} / \mathrm{m}^{2}$ and a mean 6MWD of 599 $\mathrm{m}$. This is comparable to another group of Belgian women [23] (BMI $32.3 \mathrm{~kg} / \mathrm{m}^{2}$ ), whose 6MWD was $591.3 \mathrm{~m}$. Even if the mean 6MWD in our group of women is comparable to other studies both before and one year after LRYGB the range of improved distance is wide and some women did not enhance the 6MWD more than a couple of meters despite a significant weight loss. The reason for this, for some women, might be that the test was not sensitive enough since the patient walked the maximum distance possible in 6 minutes before the surgery. Another explanation could be that some women would have needed guidance to enhance their cardiovascular endurance and walking ability when losing weight during the postoperative period.

Both fat mass and fat-free mass (FFM) decrease after weight loss and for bariatric surgical interventions, FFM-loss varies from $12.4 \%$ up to $52.7 \%$ of the weight loss [25] Although the women in our study most certainly lost FFM it did demonstrate that patients improved in all muscular endurance tests and that grip strength was preserved.
The handgrip strength was not statistically different from reference values for healthy women [17], either before or one year after LRYGB. This is in accordance with results by Hulens et al. [26] who found no statistically significant differences in handgrip strength between women with obesity or normal weight.

The women in our study reported in median 1231 MET minutes/week before and 2428 MET minutes/week one year after LRYGB, compared to a group of Swedish women (age 41.6 years, height $1.67 \mathrm{~m}$, BMI $23.2 \mathrm{~kg} / \mathrm{m}^{2}$ ) that reported a total activity level on IPAQ of 1596 MET minutes/week [27]. The women in our study sat in median 480 minutes/day before and 360 minutes/day one year after LRYGB. These figures are comparable to healthy Swedish women who spent in median 414 minutes/day sitting [27]. Even though we found a significantly improved level of physical activity one year after LRYGB, $18 \%$, (5) women were still not sufficiently physically active $>600$ MET-minutes/week and may need help to increase their physical activity level. IPAQ was primarily designed for population surveillance and according to the guidelines [21] it should not be used as an outcome measure in small-scale intervention studies. Therefore, the results need to be interpreted with caution. Nevertheless, IPAQ has for a long time been used to measure physical activity level before and after LRYGB $[8$, 28] Over-reporting is an inherent limitation of validity when 
using physical activity questionnaires in general [29] and especially in people with obesity [30]. It is concluded that even if IPAQ has acceptable criterion validity for use in Swedish adults, it significantly overestimated self-reported time spent in physical activity [27]. A systematic review by Lee et al. [31] concerning the validity of the IPAQ also concluded that it overestimated physical activity as measured by objective criterion by an average of 84 percent and that the correlation between the IPAQ and objective measures of physical activity in the large majority of studies was lower than the acceptable standard. Hence, the evidence to support the use of the IPAQ as an indicator of relative or absolute physical activity is weak. With this in mind, the results in this study considering physical activity level and time spent sitting need to be evaluated further by objective methods such as for example with accelerometers. Although the use of the same instrument (IPAQ) both before and after an intervention gives the possibility to detect differences, the same person probably over reported to the same extent at both occasions.

There was only one significant but low correlation between difference in BMI and the difference in peak grip force left hand $\left(r_{s}=0.416, p=0.028\right)$. A small sample size or large ranges in results of the included tests can explain the lack of correlation between the decrease in BMI and difference in physical activity level/fitness before and one year after LRYGB. This needs to be further evaluated in larger samples.

\section{CONCLUSION}

The physical activity level (measured with IPAQ) as well as physical fitness (measured with 6MWT and muscular endurance tests) increased and grip strength preserved in Swedish women one year after LRYGB, compared to before surgery. These improvements and the considerable weight loss are important factors in reducing the risk of developing lifestyle associated diseases and risk of premature death in this group of women. But even if both physical activity and physical fitness increased at group level one year after LRYGB, some individuals still needed to be more physically active and to enhance the physical fitness level. These patients might benefit from physiotherapy to be able to be more physically active.

\section{CONFLICT OF INTEREST}

The authors confirm that this article content has no conflicts of interest.

\section{ACKNOWLEDGEMENTS}

This study was supported by grants from the Research and Development Council of Göteborg and Bohuslän.

\section{REFERENCES}

[1] Bouchard C. Genomic predictors of trainability. Exp Physiol 2012; 97: 347-52.

[2] Caspersen CJ, Powell KE, Christenson GM. Physical activity, exercise, and physical fitness: definitions and distinctions for health-related research. Public Health Rep 1985; 100: 126-31.
[3] Hue O, Berrigan F, Simoneau M, et al. Muscle force and force control after weight loss in obese and morbidly obese men. Obes Surg 2008; 18: 1112-8.

[4] Tompkins J, Bosch PR, Chenowith R, Tiede JL, Swain JM. Changes in functional walking distance and health-related quality of life after gastric bypass surgery. Phys Ther 2008; 88: 928-35.

[5] Maniscalco M, Zedda A, Giardiello C, et al. Effect of bariatric surgery on the six-minute walk test in severe uncomplicated obesity. Obes Surg 2006; 16: 836-41.

[6] Josbeno DA, Jakicic JM, Hergenroeder A, Eid GM. Physical activity and physical function changes in obese individuals after gastric bypass surgery. Surg Obes Relat Dis 2010; 6: 361-6.

[7] WHO. Global recommendations on physical activity for health: World Health Organization. 2010.

[8] Evans RK, Bond DS, Wolfe LG, et al. Participation in $150 \mathrm{~min} / \mathrm{wk}$ of moderate or higher intensity physical activity yields greater weight loss after gastric bypass surgery. Surg Obes Relat Dis 2007; 3: 526-30.

[9] van der Ploeg HP, Chey T, Korda RJ, et al. Sitting time and allcause mortality risk in 222497 Australian adults. Arch Intern Med 2012; 172: 494-500.

[10] Bond DS, Unick JL, Jakicic JM, et al. Objective assessment of time spent being sedentary in bariatric surgery candidates. Obes Surg 2011; 21: 811-4.

[11] Matthews CE, Chen KY, Freedson PS, et al. Amount of time spent in sedentary behaviors in the United States, 2003-2004. Am J Epidemiol 2008; 167: 875-81.

[12] Physical status: the use and interpretation of anthropometry. Report of a WHO Expert Committee. World Health Organ Tech Rep Ser. 1995; 854: 1-452.

[13] Beriault K, Carpentier AC, Gagnon C, et al. Reproducibility of the 6-minute walk test in obese adults. Int J Sports Med 2009; 30: 7257.

[14] ATS statement: guidelines for the six-minute walk test. Am J Respir Crit Care Med 2002; 166: 111-7.

[15] Borg G. Perceived exertion as an indicator of somatic stress. Scand J Rehabil Med 1970; 2: 92-8.

[16] Borg G. A category scale with ratio properties for intermodal and interindividual comparisons. Psychophysical judgment and the process of perception. Geissler HG, Petzold P ed. Berlin: VEB Deutscher Verlag der Wissenschaften 1982; pp. 25-34.

[17] Nordenskiold UM, Grimby G. Grip force in patients with rheumatoid arthritis and fibromyalgia and in healthy subjects. A study with the Grippit instrument. Scand J Rheumatol 1993; 22: 14-9.

[18] Lagerstrom C, Nordgren B. On the reliability and usefulness of methods for grip strength measurement. Scand J Rehabil Med 1998; 30: 113-9.

[19] Cider Å, Carlsson S, Arvidsson C, Andersson B, Sunnerhagen KS. Reliability of clinical muscular endurance tests in patients with chronic heart failure. Eur J Cardiovasc Nurs 2006; 5: 122-6.

[20] Cider A, Carlsson S, Arvidsson C, Andersson B, Sunnerhagen KS. Reliability of clinical muscular endurance tests in patients with chronic heart failure. Eur J Cardiovasc Nurs 2006; 5: 122-6.

[21] Guidelines for data processing and analysis of the international physical activity questionnaire (IPAQ), 2005; Available from: http://www.ipaq.ki.se/scoring.pdf

[22] Munro B. Statistical methods for health and health care research. $4^{\text {th }}$ ed. Philadelphia: JB Lippincott 2000.

[23] Hulens M, Vansant G, Claessens AL, Lysens R, Muls E. Predictors of 6-minute walk test results in lean, obese and morbidly obese women. Scand J Med Sci Sports 2003; 13: 98-105.

[24] Larsson UE, Reynisdottir S. The six-minute walk test in outpatients with obesity: reproducibility and known group validity. Physiother Res Int 2008; 13: 84-93.

[25] Chaston TB, Dixon JB, O'Brien PE. Changes in fat-free mass during significant weight loss: a systematic review. Int $\mathrm{J}$ Obes 2007; 31: 743-50.

[26] Hulens M, Vansant G, Lysens R, et al. Study of differences in peripheral muscle strength of lean versus obese women: an allometric approach. Int J Obes Relat Metab Disord 2001; 25: 67681.

[27] Ekelund U, Sepp H, Brage S, et al. Criterion-related validity of the last 7-day, short form of the International Physical Activity Questionnaire in Swedish adults. Public Health Nutr 2006; 9: 25865 . 
[28] Bond DS, Phelan S, Wolfe LG, et al. Becoming physically active after bariatric surgery is associated with improved weight loss and health-related quality of life. Obesity $2008 ; 17: 78-83$.

[29] Shephard RJ. Limits to the measurement of habitual physical activity by questionnaires. Br J Sports Med 2003; 37: 197-206.
[30] Lichtman SW, Pisarska K, Berman ER, et al. Discrepancy between self-reported and actual caloric intake and exercise in obese subjects. N Engl J Med 1992; 327: 1893-8.

[31] Lee PH, Macfarlane DJ, Lam TH, Stewart SM. Validity of the International Physical Activity Questionnaire Short Form (IPAQSF): a systematic review. Int J Behav Nutr Phys Act 2011; 8: 115.

Received: January 20, 2014

Revised: June 20, 2014

Accepted: June 23, 2014

(C) Wiklund et al.; Licensee Bentham Open.

This is an open access article licensed under the terms of the Creative Commons Attribution Non-Commercial License (http://creativecommons.org/licenses/by-nc/3.0/) which permits unrestricted, non-commercial use, distribution and reproduction in any medium, provided the work is properly cited. 